\title{
O equilíbrio oscilante de Luís da Silva: discussão sobre alguns conceitos d’A teoria do romance, de Lukács
}

\author{
Rosa Lúcia Miguel Fontes \\ Mestre em Letras: Estudos Literários / UFMG
}

\begin{abstract}
RESUMO
Para Lukács, o romance tornou-se a forma estética de nosso tempo e, n’A teoria do romance, o filósofo apresenta pressupostos teóricos que estabelecem os conceitos para a constituição da narrativa, sendo eles, especialmente, a relação do escritor no seu ato criador, a ironia, a totalidade, a ação demoníaca e a perspectiva do autor como traço biográfico. Angústia é o romance a propósito dessa teoria.
\end{abstract}

\section{PALAVRAS-CHAVE}

Romance, narrativa, ironia, totalidade, ação demoníaca

O artista, porém, vive em sociedade; e - queira ou não - existe uma influência recíproca entre ele e a sociedade.

Lukács

N’A teoria do romance, Lukács mostra como o romance tornou-se a forma estética de nosso tempo e como as questões históricas e filosóficas são elementos fundamentais para o surgimento deste gênero literário. Ao tomar como ponto de partida os conceitos filosóficos que o influenciou fortemente - a filosofia de Immanuel Kant (1724-1804) e a filosofia de Hegel (17701831) - o filósofo estabelece as linhas básicas da constituição do romance e a relação entre o mundo grego e o mundo moderno. Esta reflexão tem como perspectiva a história e o pensamento filosófico do momento a ser estudado, ou seja, o momento histórico filosófico em que foi redigida a epopeia e o momento histórico filosófico em que o romance é redigido.

No ensaio, Lukács descreve o surgimento da civilização grega que explodiu com uma atividade intelectual muito influente. Antes de a filosofia evoluir, será o modelo mitológico que 
irá predominar na Grécia antiga com seus deuses representando fenômenos naturais e seus heróis gloriosos.

O pensamento mítico nasceu do desejo de dominação do mundo, para assim afugentar o medo e a insegurança. As duas grandes epopeias - Ilíada e Odisseia, de Homero - são narrativas cujos temas, formas e configurações Lukács irá estabelecer como ponto de partida para apresentar a origem do que para nós é hoje o que antes era a epopeia para os gregos: uma das maiores expressões da literatura - o romance moderno. Lukács inicia A teoria do romance apresentando esse tempo remoto. Sem um mapa físico constituído, o filósofo mostra a completa ausência do estranhamento entre o homem e o mundo, o que imperava era uma dualidade perfeita e integrada formando uma unidade entre o interior e exterior.

O mundo é vasto, e no entanto é como a própria casa, pois o fogo que arde na alma é da mesma essência que as estrelas, distinguem-se deles nitidamente, o mundo e o eu, a luz e o fogo, porém jamais se tornarão para sempre alheios um ao outro, pois o fogo é a alma de toda luz e de luz vestese todo o fogo. Todo ato da alma torna-se, pois, significativo e integrado nessa dualidade. ${ }^{1}$

Concebendo a epopeia como a época da mais "perfeita concordância dos atos com as exigências íntimas da alma: de grandeza, realização e plenitude”, 2 Lukács mostra como na epopeia ocorre a coincidência entre "ser e destino, aventura e perfeição, vida e essência (como) conceitos idênticos”. ${ }^{3}$ São termos que dizem respeito à determinação literária, ao mesmo tempo que se desconhece a dor, o sofrimento e a morte. Tais termos não partem da intencionalidade do indivíduo, mas de circunstâncias histórico-filosóficas, cuja abrangência marca a criação estética. As duas grandes "objetivações da grande literatura épica”4 são, segundo Lukács, a epopeia e o romance. O herói da epopeia não corresponde ao indivíduo isolado, mas àquele que luta pelo coletivo. Relativo a esse desenvolvimento organizado, de que é composto o mundo épico, não se destaca uma interioridade por meio do caráter pessoal do indivíduo épico. O destino do herói mescla-se com o da comunidade épica, pois seu destino está revestido, solidificado nela. "É um mundo homogêneo, e tampouco a separação entre homem e mundo, entre eu e tu é capaz de perturbar sua homogeneidade."5

\footnotetext{
${ }^{1}$ LUKÁCS. A teoria do romance: um ensaio histórico-filosófico, p. 25.

${ }^{2}$ LUKÁCS. A teoria do romance: um ensaio histórico-filosófico, p. 26.

${ }^{3}$ LUKÁCS. A teoria do romance: um ensaio histórico-filosófico, p. 27.

${ }^{4}$ LUKÁCS. A teoria do romance: um ensaio histórico-filosófico, p. 55.

${ }^{5}$ LUKÁCS. A teoria do romance: um ensaio histórico-filosófico, p. 29.
} 
Dentro dessa perfeição, o herói da epopeia não conhece os tormentos que alimentam a busca e o medo do novo. Há um círculo configurador das formas que faz da epopeia um conjunto perfeito de harmonia, tanto no interior do ser quanto no exterior. De acordo com Lukács,

(...) é sempre um sintoma de cisão entre interior e exterior, um índice da diferença essencial entre eu e mundo, da incongruência entre alma e ação. Ao sair em busca de aventuras e vencê-las, a alma desconhece o real tormento da procura e o real perigo da descoberta, e jamais põe a si mesma em jogo; ela ainda não sabe que pode perder-se e nunca imagina que terá de buscar-se. Essa é a era da epopéia. ${ }^{6}$

Mesmo com a dimensão temporal da existência humana, o homem ainda não deixou de buscar conhecimento, de tentar entender o que está exterior à sua mente. Para Lukács, a imanência pertence ao sujeito e está ligada à sua essência, que é realidade primeira e última do ser, aquilo sem o qual o ser não poderá existir ou deixará de ser o que é, uma vez que se constitui pela intencionalidade de sua consciência repleta de sentido e a transfere para a realidade.

No destino que dá forma e no herói que, criando-se encontra-se a si mesmo, a pura essência desperta para a vida, a simples vida aniquila-se perante a única realidade verdadeira da essência; para além da vida, foi alçado um nível de ser repleto de uma plenitude ricamente florescente, diante da qual a vida cotidiana não serve nem sequer de contraste. ${ }^{7}$

Na concepção hegeliana de que “a verdade é o todo”, é possível perceber o pensamento de Lukács. Se ele mostra que nos tempos helênicos o mundo era pequeno e, no entanto, vasto, o herói da epopeia conhecia o caminho que iria percorrer e, portanto, não estava sozinho, justamente por todo esse mundo fechado, havia nele a totalidade, ou seja, havia no mundo da epopeia a ideia absoluta, exemplo supremo de unidade.

O círculo em que vivem metafisicamente os gregos é menor do que o nosso: eis por que jamais seríamos capazes de nos imaginar nele com vida; ou melhor, o círculo cuja completude constitui a essência transcendental de suas vidas rompeu-se para nós; não podemos mais respirar num mundo fechado. ${ }^{8}$

Lukács também parte de pontos da filosofia de Hegel, que têm na origem “um exame do desenvolvimento pendular dos movimentos históricos” para elevá-lo “à condição de princípio de explicação histórica”. 9 Para Hegel, a realidade é sempre um devir, uma vez que um momento prepara o outro. No entanto, para que esse outro momento aconteça, é necessário

\footnotetext{
${ }^{6}$ LUKÁCS. A teoria do romance: um ensaio histórico-filosófico, p.26.

${ }^{7}$ LUKÁCS. A teoria do romance: um ensaio histórico-filosófico, p. 32.

${ }^{8}$ LUKÁCS. A teoria do romance: um ensaio histórico-filosófico, p. 30.

${ }^{9}$ RUSSELL. História do pensamento ocidental, p. 398.
} 
negar o anterior. Esses três momentos - tese, antítese e síntese - sucedem-se de maneira a nunca se fecharem. Dessa forma, a cada momento final que seria uma síntese, na verdade torna uma tese de um próximo movimento, só que de uma forma mais ampliada que,

(...) em certos aspectos, é uma reminiscência do esforço socrático em busca da forma do Bem. A este último corresponde o que Hegel chama de Idéia Absoluta. Assim como a dialética socrática, destruindo hipóteses especiais, conduz afinal à forma do Bem, igualmente a dialética hegeliana ascende à Idéia Absoluta. ${ }^{10}$

Com esses conceitos Lukács irá mostrar como a forma interna do romance vai traduzir o mundo. O herói problemático será o ser que vai representar o seu pensamento. Ele será o nada que vai se identificar com o seu ser. Será ao mesmo tempo ser e não ser, no entanto progressivo, uma vez que vai passar por cada etapa do seu processo, rumo ao seu desenvolvimento, e que dentro da forma romanesca poderá chegar a um ponto fecundo, produtivo, representando assim a modernidade. De acordo com Lukács,

(...) os elementos do romance são inteiramente abstratos: abstrata é a aspiração dos homens imbuída da perfeição utópica, que só sente a si mesma e a seus desejos como realidade verdadeira; abstrata é a existência de estruturas que repousam somente na efetividade e na força do que existe; e abstrata é a intenção configuradora que permite subsistir, sem ser superada, a distância entre os dois grupos abstratos dos elementos de configuração, que a torna sensível, sem superá-la, como experiência do homem romanesco, que dela se vale para unir ambos os grupos e portanto a transforma no veículo da composição. O perigo que surge desse caráter fundamentalmente abstrato do romance já foi reconhecido. (...) E só se pode combatê-lo na medida em que se puser como realidade última, de maneira consciente e conseqüente, a incompletude, a fragmentariedade e o remeter-se além de si mesmo do mundo. ${ }^{11}$

Os conceitos de "real” e "ideal” mostram o "caráter duplo" que o escritor tem de atentar para atingir seu “objeto de reflexão”. No ideal há um princípio, um valor que é inerente ao homem. Está ligado à sua ética, à maneira como um ser se revela como real ou sincero. O real é o existente. Ou o real existe fora da mente, uma realidade externa do ser, ou está dentro dela, uma realidade interna do ser.

Como constituinte formal da forma romanesca, significa ela uma cisão interna do sujeito normativamente criador em uma subjetividade como interioridade, que faz frente a complexos de poder alheios e empenha-se por impregnar o mundo alheio com os conteúdos de sua aspiração, e uma subjetividade que desvela a abstração e portanto a limitação dos mundos

\footnotetext{
${ }^{10}$ RUSSELL. História do pensamento ocidental, p. 397-398.

${ }^{11}$ LUKÁCS. A teoria do romance, p.70-77.
} 
reciprocamente alheios do sujeito e do objeto, que os compreende em seus limites, concebidos como necessidade e condicionamento de sua existência, e que, mediante esse desvelamento, ainda que mantenha intacta a dualidade do mundo, ao mesmo tempo vislumbra e configura um mundo unitário no condicionamento recíproco dos elementos essencialmente alheios entre si. ${ }^{12}$

Nesse sentido, a ironia, de acordo com Lukács, consiste no processo de posicionamento duplo do “indivíduo criador”, que primeiro vai refletir sobre si mesmo para depois apresentar uma reflexão sobre o mundo, reproduzindo assim o real. O autor, no seu ato criador, recria a realidade dentro do texto, sem deixar de ter a consciência de que na realidade há normas, mas também há a sua realidade, sua ética objetiva, da qual ele lança mão para retratar a realidade. Ou seja, o autor extrai da sua realidade a realidade que irá apresentar no romance, ultrapassando "a consciência de seus heróis". 13

O conceito de ironia romântica surge com Schlegel. Para o grupo de românticos alemães o que os fazia distinguir a ironia “como figura proposta pela retórica” é que ela se configurava como "forma de beleza e estaria ligada diretamente à poesia” e, também, “como objeto de estudo ou medida de criação". ${ }^{14}$ De acordo com esses pressupostos e com A teoria do romance, percebe-se que a ironia, como uma categoria estrutural, torna-se um elemento constitutivo do romance. Ademais, além desse conceito, Lukács também trabalha a ironia dentro do critério da autorreflexão; uma maneira de o sujeito se olhar como objeto, que será a base formal do romance moderno. Lukács dá ênfase ao trabalho do escritor que se põe, ao mesmo tempo, como sujeito e objeto, extraindo assim um ponto bastante sutil da ironia que se funde na composição paradoxal do romance moderno. A saber,

(...) a reflexão do indivíduo criador, a ética do escritor no tocante ao conteúdo, possui um caráter duplo: refere-se ela sobretudo à configuração reflexiva do destino que ao ideal na vida, à efetividade dessa relação como destino e à consideração valorativa da realidade. Essa reflexão torna-se novamente, contudo, objeto de reflexão: ela própria é meramente um ideal, algo subjetivo, meramente postulativo, também ela se defronta com um destino numa realidade que lhe é estranha, destino este que, dessa vez puramente refletido e restrito ao narrador, tem de ser configurado. ${ }^{15}$

Em Angústia, Graciliano Ramos, como escritor, é essencial para a estrutura narrativa, pois é ele o sujeito que dá forma ao herói, Luís da Silva, e a sua busca desesperada, de maneira coesa. Para Lukács o romancista é importante e tem papel de “elucidar um estado de

\footnotetext{
${ }^{12}$ LUKÁCS. A teoria do romance: um ensaio histórico-filosófico, p. 74-75.

${ }^{13}$ GOLDMANN. Sociologia do romance, p. 13.

${ }^{14}$ BRAIT. Ironia em perspectiva polifônica, p. 27.

${ }^{15}$ LUKÁCS. A teoria do romance: um ensaio histórico-filosófico, p. 86.
} 
fato (...) recoberto pelo tato sutilmente irônico da composição: (...) a forma exterior do romance é essencialmente biográfica” 16 e "na [sua] experiência da natureza, o sujeito apenas 'real' dissolve todo o mundo exterior em estado de ânimo e torna-se ele próprio estado de ânimo, pela inexorável identidade de essência do sujeito contemplativo com seu objeto”. ${ }^{17}$

A narrativa de Angústia constrói-se segundo o desejo do seu herói de se compreender e compreender a vida, sua existência. Luís da Silva narra sua trajetória a fim de atingir o autoconhecimento e desvelar o sentido oculto do mundo: o protagonista está em permanente busca de sentido, por não lhe ser imanente. Neste "mundo circundante" custa-lhe encontrar o real sentido da existência. Segundo Lukács, “como indício da busca autêntica ou inautêntica pelo objetivo que não é dado de modo claro e evidente”. ${ }^{18}$ As indagações e as reflexões de Luís da Silva, que percorrem toda a narrativa, podem caracterizá-lo como herói problemático; um indivíduo à procura de sentido para o mundo e para si mesmo. Suas dúvidas são expressões de uma identidade fragmentada, que quer se entender e entender o mundo igualmente fragmentado. Segundo Lukács,

(...) os heróis como homens vivos, em meio a uma massa circundante presa simplesmente à vida de modo a fazer com que, do tumulto de uma ação onerada pelo peso da vida, resplandeça pouco a pouco o claro destino da vida. (...) Com isso, o herói tornou-se polêmico e problemático; ser herói não é mais a forma natural de existência da esfera essencial. ${ }^{19}$

À medida que Luís da Silva, como um herói moderno, fracassa e reconhece a inutilidade da luta e a supremacia do real, a melancolia e a resignação tomam conta dele e faz com que sua psicologia seja o campo da ação do demoníaco. Demoníaco como ambíguo. Lukács o circunscreve mais em termos do que não é: não é dotado de razão; não é humano; nem diabólico; nem angélico; parece gostar do impossível e recusar o possível com desprezo; é parecido ao acaso e ao arbitrário, comprimindo o tempo e expandindo o espaço. A ação demoníaca será o fio condutor que irá caracterizar o herói moderno, surgindo assim a solidão e a problemática do indivíduo romanesco. De forma que

\footnotetext{
${ }^{16}$ LUKÁCS. A teoria do romance: um ensaio histórico-filosófico, p. 77.

${ }^{17}$ LUKÁCS. A teoria do romance: um ensaio histórico-filosófico, p. 65.

${ }^{18}$ LUKÁCS. A teoria do romance: um ensaio histórico-filosófico, p. 38.

${ }^{19}$ LUKÁCS. A teoria do romance: um ensaio histórico-filosófico, p. 41.
} 
(...) o colapso do um do objetivo, também o sujeito torna-se um fragmento; somente o eu permanece existente, embora também sua existência dilua-se na insubstancialidade Do mundo em ruínas criado por ele próprio. ${ }^{20}$

O espelhamento é percebido como um traço bastante marcante. $\mathrm{O}$ romancista põe o personagem em situações concretas: o que é correto dentro de uma sociedade não se pode moldar em causas particulares. Dessa forma, o romancista representa ao que Lukács chama de duas éticas. Daí decorre a posição do escritor no seu ato de criação. De acordo com A teoria do romance e, em se tratando de Angústia, esse é o ponto do caráter reflexivo da obra.

Em Angústia, há muito da infância de Luís da Silva na infância de Graciliano, há muitas atitudes de Luís da Silva bem parecidas com as do autor. Como Graciliano já mencionou: "Nunca pude sair de mim mesmo, só posso escrever o que sou”. ${ }^{21}$ Dessa forma, ao observar a variedade de histórias e situações vividas pelo personagem, será realçado um traço marcante da linguagem de Graciliano Ramos, a ironia, na forma de reflexo e reflexão.

Lidando com essas razões no romance e levando em consideração a ironia como traço de representação do autor no discurso, sobressai Graciliano Ramos que sempre recusou o modo de vida capitalista e durante toda a sua vida agiu dentro de um mesmo princípio ético. Pondo lado a lado Luís da Silva e Julião Tavares, ambos os personagens servirão para que o autor possa mostrar aquilo que para ele era ultrajante na sociedade e como ele liquida o ultraje: Luís da Silva enforca Julião Tavares. A ironia, para Lukács é a

(...) auto-superação da subjetividade que foi aos limites, é a mais alta liberdade possível num mundo sem deus. Eis por que ela não é meramente a única condição a priori possível de uma realidade verdadeira e criadora da totalidade, mas também eleva essa totalidade, o romance, a forma representativa da época, na medida em que as categorias estruturais do romance coincidem constitutivamente com a situação do mundo. ${ }^{22}$

Graciliano Ramos, no seu “ato criador”, cria uma representação dialética na qual impele seu personagem a rever seu passado à luz do seu presente. As reminiscências de Luís da Silva fazem com que ele questione o seu presente em nome de um futuro, ou seja, o que está sendo em nome do que ainda não o é. Nessa dialética, Graciliano Ramos faz com que Luís da Silva busque uma explicação de sua realidade, baseando-se na oposição da sua existência, quer seja, o capitalismo representado por Julião Tavares e a própria maneira de ser de Luís da Silva, de maneira que o protagonista vai encarar sua realidade de forma bastante cruel. Seus

\footnotetext{
${ }^{20}$ LUKÁCS. A teoria do romance: um ensaio histórico-filosófico, p. 52.

${ }^{21}$ BRAYNER. Graciliano Ramos, p. 55.

${ }^{22}$ LUKÁCS. A teoria do romance: um ensaio histórico-filosófico, p. 96.
} 
sentimentos irão confundir-se e surgirá um processo interno e intenso na busca de compreensão da realidade desesperadora que é a sua condição humana. Ele vai tornar-se mais do que nunca um indivíduo inconformado que luta para superar as barreiras e a mediocridade de sua vida solitária.

Sendo assim, ao criar na tessitura do romance o mundo conflituoso e sufocante de Luís da Silva, torna-se perceptível o propósito de Graciliano, que cria Luís da Silva para falar por ele, ao mesmo tempo em que ele fala por meio de Luís da Silva, especialmente quando este se mostra dilacerado por dois motivos: sentir-se um sujeito menor diante de uma sociedade capitalista e excluído de uma burguesia capitalista a qual Julião Tavares representava. Segundo Lukács,

(...) a ética é um pressuposto puramente formal que, por sua profundidade, torna possível um avanço até a essência formalmente condicionada, por sua extensão possibilita a totalidade igualmente condicionada pela forma e que, por sua amplitude, realiza o equilíbrio dos elementos constitutivos. (...) No romance intenção, a ética, é visível na configuração de cada detalhe e constitui, portanto, em seu conteúdo mais concreto, um elemento estrutural eficaz da própria composição literária. Assim, o romance, em contraposição à existência em repouso na forma consumada dos demais gêneros, aparece como algo em devir, como um processo. ${ }^{23}$

Por ser narrado em primeira pessoa, a voz de Luís da Silva se confunde e se entrelaça com a voz de Graciliano Ramos. Luís da Silva, o narrador, vive a história; Graciliano Ramos, o autor, narra a história. Percebe-se essa aproximação, uma vez que o narrador, Luís da Silva, não se põe distante do seu passado, pelo contrário, ele revive intensamente os acontecimentos e seus sentimentos de outrora. Há momentos em que se distingue a voz de Luís da Silva, como narrador personagem, em alguns outros, será a voz de Graciliano Ramos que estará subjacente à narrativa. Nesse processo, há o indicativo de uma consciência das normas estabelecidas, não obstante, haver também o indicativo da consciência do autor, sua ética objetiva que ele lança mão para retratar a realidade, gerando, dessa forma, as duas éticas.

Lukács confere a luta interna do herói ao “mundo abandonado por deus”, quando a “alma que sai a campo para conhecer a si mesma”, ${ }^{24}$ por conseguinte, Luís da Silva representa essa “alma” que está no momento de “conhecer a si mesma”. Ele é um indivíduo participante do mundo e, com uma trajetória de vida marcada, sobretudo, por uma formação intelectual, o herói tem a consciência dolorosa de todas as transformações que o cerca. Ele se define por sua

\footnotetext{
${ }^{23}$ LUKÁCS. A teoria do romance: um ensaio histórico-filosófico, p. 72.

${ }^{24}$ LUKÁCS. A teoria do romance: um ensaio histórico-filosófico, p. 91.
} 
existência e como essa existência condiciona a relação dele consigo próprio, ou seja, suas escolhas. Como ele mesmo diz, suas "ações surgem baralhadas e esmorecidas, como se fossem de outra pessoa. Penso nelas com indiferença. Certos atos aparecem inexplicáveis. Até as feições das pessoas e os lugares por onde transitei perdem a nitidez.”25

No início do romance, Luís da Silva está imerso em uma crise que o comprime e faz dele um ser alucinado. O protagonista recupera-se de um período de alucinação. Luís da Silva cruza todo o romance e dispara com intensidade certo período de sua vida, entrecortando-o com passagens de sua infância até a vida adulta. O anseio de Luís da Silva em alcançar a totalidade fez dele um indivíduo em desarmonia, em desequilíbrio constante, tanto o seu mundo exterior quanto interior está dissonante. Contudo, essa forma de ser do protagonista condiz com as narrativas modernas, pois a forma do romance estudada por Lukács não somente reproduz fatos, mas, especialmente, revela os sentimentos que avassalam a alma humana. O romance para Lukács,

(...) é a forma da aventura do valor próprio da interioridade; seu conteúdo é a história da alma que sai a campo para conhecer a si mesma, que busca aventuras para por elas ser provada e, pondo-se à prova, encontrar a própria essência. A segurança interior do mundo épico exclui a aventura, nesse sentido próprio: os heróis da epopéia percorrem uma série variegada de aventuras, mas que vão superá-las, tanto interna quanto internamente. ${ }^{26}$

Luís da Silva busca tenazmente o sentido da vida. Na forma do romance, Graciliano Ramos o determina e o individualiza. A principal característica desse herói é viver a sua essência num determinado momento de sua vida na forma romanesca que também o atualiza. Ele apresenta todas as dificuldades, todas as contradições em que vive.

Na visão de Lukács, o romance mostra a distância entre o mundo real e a ideia utópica do homem em busca da harmonia. Essa dissonância não resolvida como experiência do herói, Lukács a considera como o veículo do romance. Já a finalidade do romance é a imanência do sentido que a forma exige, cujo resultado é uma rigorosa demonstração da sua ausência.

Se na epopeia o herói faz parte de um todo e sua história reflete a homogeneidade da comunidade, não é isso que ocorre em Angústia. Luís da Silva é um personagem centrado, sua narrativa, carregada de subjetividade, com seu eterno conflito em relação às pessoas e sua inadequação na sociedade. Isso se reflete pela forma como inicia e termina sua narrativa; entrecortada pelas recordações de sua infância, pelas suas viagens, suas aventuras. Essa forma

\footnotetext{
${ }^{25}$ RAMOS. Angústia, p. 106.

${ }^{26}$ LUKÁCS. A teoria do romance: um ensaio histórico-filosófico, p. 91.
} 
de ser do personagem perpassa também o romance e esse é um dos sinais que o diferencia da epopeia; o herói sendo fragmentado, o romance também se torna fragmentado. Essa perspectiva de apresentar o romance elevando a subjetividade do personagem, mostrando todo o seu processo de adequação à sociedade, as relações com outros personagens, sejam efetivas, políticas ou de amizade, leva a um resultado de apresentar o sujeito socialmente. Ao destacar todos os dilemas, toda a solidão do herói, o romance revela um ser dentro do seu contexto histórico e social. Luís da Silva representa mais do que esse homem moderno num mundo abandonado por deus, buscando algo mais sem se entregar passivamente ao desespero - ele representa e reflete sua existência como homem e escritor.

\begin{abstract}
To Lukács, the novel has become the aesthetics form of our time. In The novel theory, the philosopher presents theorical assumptions that stablish the concepts of the novel story constitution. They are, specially, the relation of the writer in his creative act: irony, totality, devil's action and the author perspective as biography sketch. Angústia is the novel measure of this theory.
\end{abstract}

\title{
KEYWORDS
}

Novel, story, irony, totality, devil’s action

\section{REFERÊNCIAS}

BRAYNER, S. (Org.). Graciliano Ramos. 2. ed. Rio de Janeiro: Civilização Brasileira, 1978.

BRAIT, Beth. Ironia em perspectiva polifônica. Campinas-SP: Editora Unicamp, 1996.

GOLDMANN, L. Sociologia do romance. Trad. Álvaro Cabral. Rio de Janeiro: Civilização Brasileira, 1967.

LUKÁCS, G. A teoria do romance: um ensaio histórico filosófico. Trad. Posfácio e notas de José Marcos Mariani de Macedo. São Paulo: Editora 34; Duas Cidades. 2000.

RAMOS, G. Angústia. 53. ed. São Paulo: Record, 2001.

RUSSELL, B. História do pensamento ocidental. A aventura dos pré-socráticos a Wittgenstein. Trad. Laura Alves e Aurélio Rebello. Rio de Janeiro: Ediouro. 2001. 